\title{
Primary Hydatid of Adductor Muscle of Thigh: A Rare Entity
}

\author{
Singh P, Pandey S, Ahirwar V \\ Department of Radiodiagnosis, BMC, Sagar, MP, India
}

Received: April 10, 2019

Accepted: May 20, 2019

Published: June 30, 2019

Cite this paper:

Singh P, Pandey S, Ahirwar V. Primary Hydatid of Adductor Muscle of Thigh: A Rare Entity. Nepalese Journal of Radiology 2019;9(13):30-32. https://doi.org/10.3126/njr.v9i1.24814

\begin{abstract}
Primary Muscle involvement of hydatid disease is a rare entity. Radiological diagnosis can be difficult at times as it mimics soft tissue tumor. Multiple imaging studies are available to detect it preoperatively. We hereby report an in a male patient with hydatid disease of adductor group of muscles of right thigh diagnosed on ultrasound followed by MRI and confirmed on surgery and histopathological examination.
\end{abstract}

Keywords: Hydatid disease; Echinococus; Adductor Muscle

\section{INTRODUCTION}

Primary hydatid of muscle is a rare entity, accounting for approximately $3-5 \%$ of all cases. ${ }^{1}$ High lactic acid concentration of the skeletal muscles is one of the important reason behind non-hostile environment for hydatid to infest in the muscles. ${ }^{2}$ Most of the previously reported cases show that quadriceps, gluteus and adductor group of muscle are commonly involved by hydatid in decreasing frequency. ${ }^{3,4,5}$ Mseddi et al reported 11 intramuscular hydatid cysts in a period of 17 years. ${ }^{6}$ It has been postulated that the larvae passes through the liver and lung pre-capillary anastomosis between pre and post parenchymal circulation and thus reaches to the muscle where it manifests as hydatid cyst.

\section{CASE REPORT}

A sixty year old male presented with swelling in right thigh which was associated with pain while walking. The swelling was tender on palpation. There was no history of fever or

Correspondence to: Dr. Somshankar Pandey

Senior Resident

Department of Radiodiagnosis

BMC, Sagar, MP, India

E-mail: somshankar.jnv@gmail.com weight loss. He had no past history of surgery or trauma. On physical examination range of motion was normal, peripheral pulsation was 
intact and inguinal lymphadenopathy was absent. Routine chemical analysis was found to be within normal limit.

Ultrasonography (USG) of the swelling revealed multiloculated cystic lesion involving adductor group of muscle of thigh (Figure 1). Vascularity on Doppler was absent. USG abdomen revealed no abnormality. MRI showed multiple hyper intense cystic lesions in T2 weighted imaging sequence suggestive of multiple daughter cysts in adductor muscle (Figure 2). The Planes between the lesions and the femoral vessels were well preserved. Marrow signal intensity on femoral and acetabular aspect of bilateral hip joints was normal. Bilateral sacroiliac joint and pelvic bones showed no abnormality. On surgical exploration, glistening white rounded cystic structure was noted (Figure 3). Histopathological analysis confirmed the diagnosis of isolated primary hydatid of adductor muscles of right thigh.

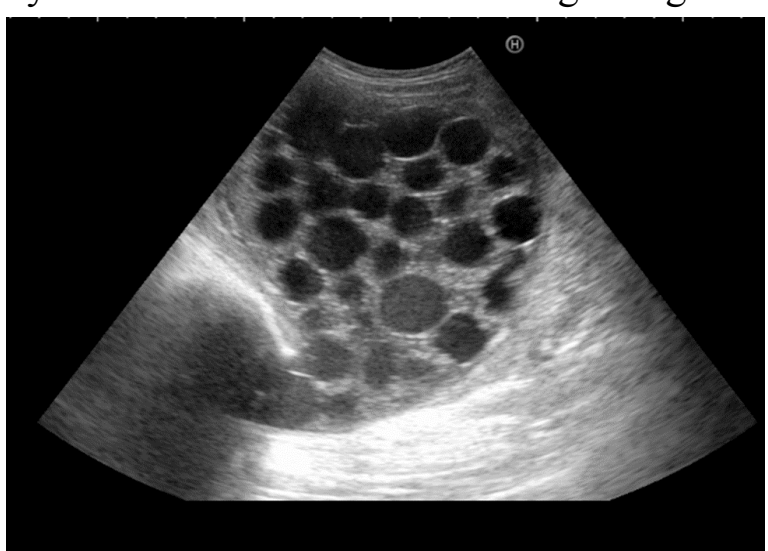

Figure 1: USG showing intramuscular multiloculated cystic lesion representing daughter cysts.

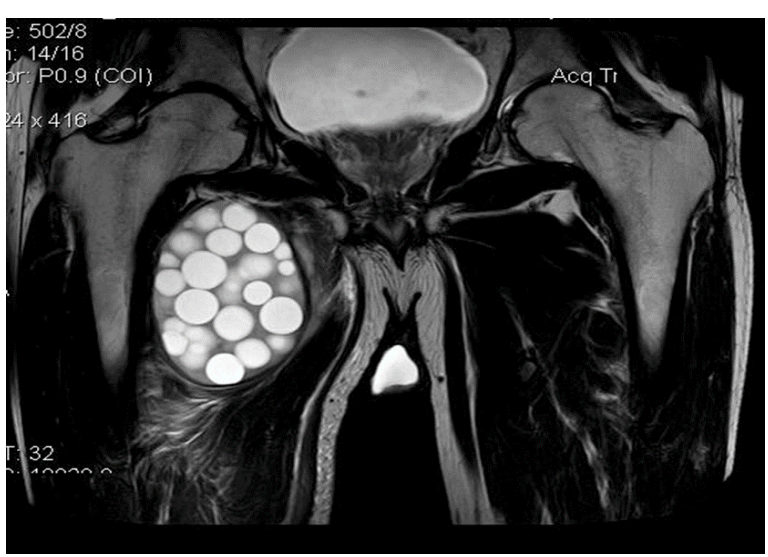

Figure 2: T2 weighted MRI showing intramuscular multiple well defined T2 hyperintese lesion confirming daughter cysts.



Figure 3: Showing surgical exploration of pearly white daughter cysts.

\section{DISCUSSION}

Hydatid disease is a zoonosis caused by the larval stage of the Echinococcus tapeworm most commonly E. granulosus and E. multilocularis. USG is the primary investigation of choice because it shows characteristic findings such as cystic nature, daughter cysts, membranes \& septa, hydatid sand and water lily sign i.e. air-fluid level with collapsed floating membranes inside the cyst. Differential diagnoses of such lesion include abscess, chronic hematoma, and necrotic soft tissue tumor. In case of abscess, CT and MRI show rim enhancement with contrast. Similarly, variable enhancement is also seen in case of soft tissue tumors in CT and MRI scans. Hematoma can be distinguished by MRI scans as the blood products are seen well in certain sequences of MRI. CT is best for detecting calcification and osseous involvement whereas MR imaging is helpful in evaluation of the loco-regional extent of the lesion and relations with the nerve and vascular pedicles. ${ }^{7,8}$ Hydatid cyst in the bone and muscle induces less antibody response so it is difficult to detect by serological methods than in other regions. ${ }^{9}$ Thus, imaging plays crucial role in diagnosis and management of intramuscular hydatid.

\section{CONCLUSION}

Hydatid cyst in unusual anatomic locations may make diagnosis challenging. Any complex cystic intramuscular mass especially 
in endemic zone should be considered as hydatid as a differential diagnosis.

\section{CONFLICT OF INTEREST}

None

\section{SOURCES OF FUNDING}

None

\section{REFERENCES}

1. Tatari H, Baran $\mathrm{O}$, Anlidag $\mathrm{T}$ et al. Primary intramuscular hydatidosis of supraspinatus muscle. Arch Orthop Trauma Surg 2001;121:93-94. https://doi.org/10.1007/PL00013775

2. Duncan GJ, Tooke SM. Echinococcus infestation of the biceps brachii. Clin Orthop 1990;261:247-250.

https://doi.org/10.1097/00003086199012000-00029

3. Ozkoç G, Akpinar S, Hersekli MA, Ozalay M, Tandoðan R. Primary hydatid disease of the quadriceps muscle: A rare localization. Arch Orthop Trauma Surg 2003;123:314-316.

https://doi.org/10.1007/s00402-003$\underline{0512-1}$

4. Ates M, Karakaplan M. Hydatid cyst in the biceps and gluteus muscles: Case report. Surg Infect (Larchmt) 2007;8(4):475-478. https://doi.org/10.1089/sur.2006.040

5. Meddeb N, Bachrouch N, Elleuch M et al. Hydatid cyst of the adductor muscles. MRI aspect, Apropos of 1 case. Bull Soc Pathol Exot 2001;94(2):106-108.

Available from: https://www.ncbi.nlm. nih.gov/pubmed/11475025 [Accessed 28th April 2019].
6. Mseddi M, Mtaoumi M, Dahmene J et al. Hydatid cysts in muscles eleven cases. Rev Chir Orthop Reparatrice Appar Mot 2005;91(3):267-271.

https://doi.org/10.1016/S00351040(05)84313-2

7. Kerimoglu U, Kapicioglu S, Emlik D, Arazi M, Ural O. Case 161: Hydatid disease with water lily sign manifesting as a soft-tissue mass in the calf of a child. Radiology 2010;256(3):1007-1010. https://doi.org/10.1148/radiol.10081066

8. Arkun R, Mete BD. Musculoskeletal hydatid disease. Musculoskelet Radiol 2011;15:527-540.

https://doi.org/10.1055/s-0031-1293498

9. Eckert J, Gemmell MA, Meslin FX, Pawlowski ZS. WHO/OIE manual on echinococcosis in humans and animals: a public health problem of global concern. Paris. World Organization for Animal Health 2002;20-72.

Available from: https://apps.who.int/iris/ handle/10665/42427 [Accessed 15th April 2019]. 